\title{
The Evolution of the Ribosomal Protein-MDM2-p53 Pathway
}

\author{
Chad Deisenroth, ${ }^{1}$ Derek A. Franklin, ${ }^{2,3}$ and Yanping Zhang ${ }^{2,3}$ \\ ${ }^{1}$ The Hamner Institutes for Health Sciences, Institute for Chemical Safety Sciences, Research \\ Triangle Park, North Carolina 27709 \\ ${ }^{2}$ Department of Radiation Oncology and Lineberger Comprehensive Cancer Center, University \\ of North Carolina at Chapel Hill, Chapel Hill, North Carolina 27599 \\ ${ }^{3}$ Department of Pharmacology, University of North Carolina at Chapel Hill, Chapel Hill, North Carolina 27599 \\ Correspondence: ypzhang@med.unc.edu
}

The progression of our understanding of ribosomal proteins as static building blocks of the ribosome to highly integrated sensors of p53 surveillance and function has achieved a tremendous rate of growth over the past several decades. As the workhorse of the cell, ribosomes are responsible for translating the genetic code into the functional units that drive cell growth and proliferation. The seminal identification of ribosomal protein binding to MDM2, the negative regulator of $\mathrm{p} 53$, has evolved into a paradigm for ribosomal protein-MDM2-p53 signaling that extends into processes as diverse as energy metabolism to proliferation. The central core of signaling occurs when perturbations to rRNA synthesis, processing, and assembly modulate the rate of ribosome biogenesis, signaling a nucleolar stress response to p53. This has led to identification of a number of disease pathologies related to ribosomal protein dysfunction that are manifested as developmental disorders or cancer. Advancing research into the basic mechanics of ribosomal protein-MDM2-p53 signaling is paving the way for novel translational research into biomarker identification and therapeutic strategies for ribosome-related diseases.

C ell growth and division are two fundamental processes essential for sustaining cell viability and yielding successive progeny. As maintained under a larger gene regulatory system, there exists tight coupling between the two processes to enable homeostatic control. Cellcycle regulation, an inherent function of proliferation, is governed by the activity of tumor protein p53 (TP53 or p53). Emerging evidence is revealing signaling pathways that converge on p53 to connect protein synthesis, the driving force behind cell growth, to regulation of the cell cycle, in which much of cell division is governed.

Protein synthesis is essential for translating the genetic code into functional units of the cellular machinery. At the core of this process is the ribosome, a complex comprised of ribosomal proteins, auxiliary factors, and ribosomal RNA. The dynamic response of a cell to ongoing external perturbations requires that protein synthesis be aligned with ribosome assembly

Editors: Guillermina Lozano and Arnold J. Levine

Additional Perspectives on The p53 Protein available at www.perspectivesinmedicine.org

Copyright (C) 2016 Cold Spring Harbor Laboratory Press; all rights reserved; doi: 10.1101/cshperspect.a026138

Cite this article as Cold Spring Harb Perspect Med 2016;6:a026138 
C. Deisenroth et al.

to maintain efficiency in growth maintenance and homeostasis.

In mammalian cells, ribosome biogenesis occurs through the coordinated assembly of equimolar concentrations of ribosomal proteins and ribosomal RNA to generate the mature $80 \mathrm{~S}$ ribosome. This process requires the activity of RNA polymerase I (POLI) to generate the $47 \mathrm{~S}$ precursor rRNA from clusters of rDNA tandem repeat genes. The precursor is further processed to $18 \mathrm{~S}, 5.8 \mathrm{~S}$, and $28 \mathrm{~S}$ rRNAs. The fourth rRNA, $5 \mathrm{~S}$, is transcribed separately by RNA polymerase III and actively imported to the nucleus for incorporation into the large subunit. The pool of 79 ribosomal proteins are actively transcribed by RNA polymerase II, exported to the cytosol for translation, and imported to the nucleolus for assembly. In addition, there are $>200$ auxiliary factors that assist in the processing of rRNA, assembly of the small and large subunits, and finally export and maturation of the functional ribosome (Boisvert et al. 2007).

Ribosome synthesis occurs in the nucleolus, a non-membrane-bound structure residing within the nucleus. Ribosomal DNA (rDNA) gene clusters form a nucleolar organization region comprised of a fibrillar center where rDNA is transcribed, a dense fibrillar component where rRNA undergoes extensive modification and cleavage processing, and a granular component where the bulk of the ribosomal proteins reside and assist in ribosomal subunit assembly. An estimated $30 \%$ of nucleolar proteins are involved in ribosome biogenesis, marking the nucleolus as the central location for ribosome assembly (Boisvert et al. 2007). Disruption of ribosome biogenesis is detrimental to normal cellular functions. Surveillance of this disruption, or "nucleolar stress," is performed by ribosomal proteins that regulate MDM2-p53 function.

\section{EXTRARIBOSOMAL FUNCTIONS OF RIBOSOMAL PROTEINS}

The fundamental structural role of ribosomal proteins is to stabilize small and large ribosome subunits, but they have been reported to be integrated into additional divergent processes of pre-ribosomal particle assembly, including rRNA folding, stabilization, processing, and transport (Tschochner and Hurt 2003). Although many of these functions are inherent to ribosome assembly, maturation, and function, ribosomal proteins have been reported to have a number of extraribosomal functions related to cell growth and division, as well as cell death (Lindström 2009).

One of the seminal processes of extraribosomal protein function identified is regulation of cell growth and proliferation. A key master regulator of cell growth is the mechanistic target of rapamycin (mTOR) kinase. Phosphorylation of ribosomal protein S6 (RPS6) via mTOR signaling directly modulates the rate of protein synthesis. Knockin mice containing a nonphosphorylatable allele of Rps6 show increased rates of protein synthesis and cell division but at the expense of normal cell growth, indicating the importance of Rps6 in driving optimal growth conditions (Ruvinsky and Meyuhas 2006). Interestingly, conditional deletion of Rps6 in mouse hepatocytes has no effect on mitogenic stimulated growth, but does inhibit proliferation (Volarevic et al. 2000). These observations are similar to T-cell-mediated Rps6 mouse knockouts, in which monoallelic depletion is sufficient to inhibit proliferation and biallelic deletion completely inhibits T-cell maturation (Sulic et al. 2005). The results show the importance of RPS6 in coordinating the growth-promoting effects of mTOR with cell-cycle dynamics.

Control of p53 translation, posttranslational stability, and activity are all key mechanisms of p53-mediated cell-cycle control with contributing roles from ribosomal proteins. Genotoxic stress induces DNA-damage-signaling cascades that activate p53-dependent cell-cycle arrest. Largely considered a posttranslational response, RPL26 has been shown to enhance the translation rate of p53 mRNA transcripts to facilitate the response to cells undergoing irradiation-induced DNA damage (Takagi et al. 2005). Protein stability of p53 is monitored by MDM2, an E3 ubiquitin ligase that ubiquitinates p53 for targeted proteasomal degradation. Binding and inhibition of MDM2 by ribosomal proteins RPL5 (Dai and Lu 2004), RPL11 (Lohrum et al. 
2003; Zhang et al. 2003b; Dai et al. 2006), RPL23 (Dai et al. 2004; Jin et al. 2004), RPS7 (Chen et al. 2007), and others continuing to be identified are emerging as critical regulators of p53 activity.

Regulation of gene transcription has been described for several ribosomal proteins. For instance, the transcription factor $\mathrm{CHOP}$ (GADD153) is up-regulated during erythroid differentiation and regulates activity of $\mathrm{CEB} / \mathrm{P}$ to control a subset of genes contributing to robust differentiation. RPS3a can bind to CHOP to alter $\mathrm{CHOP}-\mathrm{CEB} / \mathrm{P}$ transcriptional activity and inhibit erythroid lineage progression (Cui et al. 2000). Multifunctional RPS3 has also been reported to bind as a non-Rel subunit of the nuclear factor $\kappa \mathrm{B}(\mathrm{NF}-\kappa \mathrm{B})$ complex to modulate DNA-binding (Wan et al. 2007). Additional ribosomal protein coregulators of transcription factor complexes are RPL7 with the vitamin D receptor (VDR) (Berghofer-Hochheimer et al. 1998), RPL11 with c-Myc (Dai et al. 2007) and $\operatorname{PPAR} \alpha$ (Gray et al. 2006), and RPL23 as an indirect regulator of Miz-1 (Wanzel et al. 2008). Aberrant ribosomal proteins levels, be it overexpression or deficiency, can be detrimental to efficient ribosomal synthesis, so self-regulation of ribosomal protein expression levels by both transcriptional and translational means are necessary. RPS14 overexpression is regulated through a negative feedback loop, whereby the free protein can suppress self-gene transcription (Tasheva and Roufa 1995). Similarly, RPS13 expression is autoregulated by a positive feedback loop, in which RPS13 protein binding moderates pre-mRNA splicing events of its own transcript (Malygin et al. 2007). Translation of general mRNA, as well as targeted transcripts, by RPL7 and RPL13a also appears to be an important component of ribosome function modulation (Neumann et al. 1995; Mazumder et al. 2003). Additional functions ascribed to ribosomal proteins include modulation of DNA repair (Hegde et al. 2004a,b; Yadavilli et al. 2007), cell migration and invasion (Liu et al. 2007; McDonald et al. 2008; Yang et al. 2013), and regulation of cell differentiation (Uechi et al. 2006, 2008; Duan et al. 2011; Yadav et al. 2014). As research progresses, identification of extraribosomal functions are likely to extend to numerous cellular processes, emphasizing the importance of their regulatory roles.

\section{p53 SURVEILLANCE OF NUCLEOLAR STRESS}

A number of studies have alluded to "nucleolar stress" as the key event capable of inducing the ribosomal protein-MDM2-p53 stress response. Within this context, nucleolar stress specifically refers to perturbations of ribosome biogenesis and the subsequent breakdown of nucleolar structure, resulting in p53 activation. These observations, in part, have led to the hypothesis of the nucleolus as a central stress response regulator for activation of p53 (Fig. 1) (Rubbi and Milner 2003).

Perturbations to rRNA synthesis, processing, and posttranslational modification can all disrupt ribosome biogenesis to trigger nucleolar stress and activate a p53-dependent response. Pharmacological inhibition of RNA POLI by the antineoplastic compound actinomycin D disrupts synthesis of $47 \mathrm{~S}$ rRNA precursor and results in p53 stability (Perry 1963; Sobell et al. 1971; Blattner et al. 1999). The retinoblastoma (Rb) tumor suppressor has been shown to bind upstream binding factor (UBF) to prevent proper assembly of the POLI transcription complex responsible for precursor $47 \mathrm{~S}$ rRNA in mouse fibroblasts (Hannan et al. 2000). Moreover, tumor suppressors p53 and PTEN inhibit the UBF-RNA POLI complex through proteinprotein interactions with the SL1 subunit (Zhai and Comai 2000; Zhang et al. 2005).

In similar fashion, rRNA transcription is impaired through misincorporation of nonfunctional nucleotide analogues into nascent transcripts. One example is the metabolite of 5-fluorouracil, 5-fluorouridine triphosphate, which misincorporates as a uracil substitution and has been identified to enhance the association of RPL5, RPL11, and RPL23 with MDM2 to activate p53 (Longley et al. 2003; Sun et al. 2007). Another example is mycophenolic acid (MPA), a compound that inhibits inosine monophosphate dehydrogenase, resulting in depletion of guanine nucleotide pools and depletion of rRNA synthesis (Huang et al. 2008). Loss 
C. Deisenroth et al.

Nucleolar stress

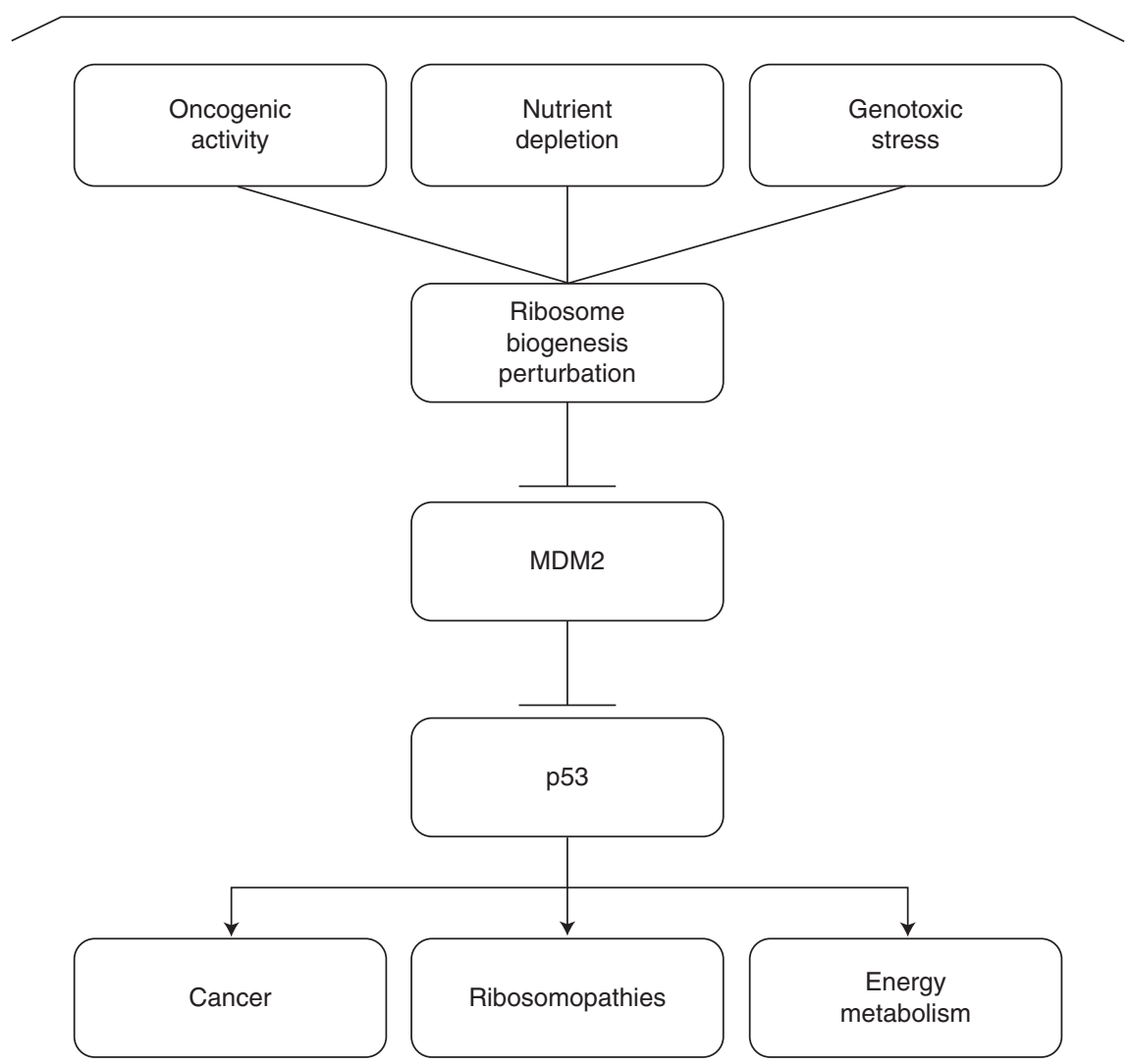

Figure 1. Overview of the ribosomal protein-MDM2-p53 pathway. Nucleolar stressors, like oncogenic activity, nutrient depletion, or genotoxic stress, can perturb aspects of ribosome biogenesis. Disruptions to rRNA or ribosomal protein synthesis, processing, transport, assembly, and function can all lead to ribosomal protein inhibition of MDM2, resulting in p53 stabilization and transactivation. Downstream consequences of p53 activation can manifest as cancer, various ribosomopathies, or modulation of cellular energy metabolism.

of POLI function, by pharmacological or chemical inhibition, has also been shown to induce nucleolar stress. Mouse embryonic fibroblasts (MEFs) lacking expression of TIF1A, a member of the POLI transcription complex, show attenuation of rRNA transcription, elevation of p53, and activation of apoptosis (Yuan et al. 2005). Moreover, depletion of additional cofactors essential for rRNA transcription have been shown to elevate nucleolar stress. Loss of the U3 small nucleolar RNA-containing RNP complex protein, BAP28, triggers p53-dependent apoptosis in zebrafish (Yuan et al. 2005). Likewise, inhibition of UBF (Ayrault et al. 2006), TIF-IA (Parlato et al. 2008), or SL1 complex recruitment
(Zhang et al. 2005) to rDNA promoters activate p53-dependent responses through mechanisms that may include decreased rRNA transcription.

Ribosomal protein imbalances resulting from individual protein depletion induce p53 accumulation and transactivation. Knockdown of either the 40S small subunit protein, RPS9 (Lindström and Zhang 2008), or the 60S large subunit RPL29 (Liu et al. 2006) in human cell lines, impacts cell-cycle kinetics, proliferation, and differentiation. Partial imbalances achieved through siRNA knockdown of RPL11 (Bhat et al. 2004), RPL5 (Dai and Lu 2004), RPS7 (Zhu et al. 2009), and RPS3 (Yadavilli et al. 2009) were found to be important for achieving 
p53 stabilization in response to nucleolar stress, but otherwise had little effect in the absence of any additional form of stress. The observations are different for RPL23 knockdown, in which p53 is activated even in the absence of an exogenous stressor, indicating that not all protein imbalances may have equal contributions to p53 regulation (Jin et al. 2004). Novel insights to ribosomal protein imbalances have also been gleaned from in vivo studies. For instance, ablation of Rps6 in T cells of mice inhibits T-cell development and subsequent accumulation in the spleen and lymph nodes in a manner dependent on p53 (Sulic et al. 2005). Like Rps6, depletion of Rpl22 was identified to selectively block lineage progression of $\alpha \beta$ T cell by inducing p53-dependent cell-cycle arrest (Anderson et al. 2007). In the liver of mice, hepatocytes deficient for Rps6 also activate p53 via a mechanism dependent on Rpl11 (Fumagalli et al. 2009). RPS6 haploinsufficency in developing frog oocytes leads to perigastrulation lethality as a result of p53-mediated apoptosis (Panic et al. 2006). Additional phenotypes displaying gene-specific characteristics are reduced body size in Rps19 and Rps20 knockout mice, as well as hyperpigmentation of the skin owing to exacerbated expression of melanocyte-specific KIT ligand that is p53 dependent (McGowan et al. 2008). This is also seen in Belly Spot and Tail (BST) mice, in which a spontaneously occurring point mutation in Rpl24 confers skin hyperpigmentation, as well as congenital malformations of the eye and skeleton, although absolute p53 dependence has not been clearly shown (Tang et al. 1999; Oliver et al. 2004). The function of an in vivo ribosomal proteinMDM2-p53 pathway is supported by gene-specific knockout models, but full appreciation for the scope of ribosomal protein imbalances on disruption of nucleolar function are warranted.

Preservation of posttranscription rRNA fidelity is a key function for maintaining a pool of competent ribosomes. Genetic models investigating the perturbation of rRNA processing factors have highlighted the essential nature of these components in surveillance of nucleolar integrity. BOP1 is part of a multicomponent complex essential for correct pre-rRNA process- ing; mediating cleavage at the internal transcribed spacers ITS1 and ITS2 to generate 25S and 5.8S rRNA (Strezoska et al. 2002). Inhibition of wild-type Bop1 in mouse 3T3 cells via expression of a dominant-negative mutant blocks production of mature rRNA transcripts, thereby inhibiting ribosome biogenesis and activating p53 (Pestov et al. 2001). Further, disruption of Wrd12, a binding partner of Bop1, has been shown to render similar effects on the cell cycle by activating p53, specifically in an ARF-independent manner, suggesting that an ribosomal protein-MDM2-p53 pathway may mediate this response (Sugimoto et al. 2003; Holzel et al. 2005). Deficiency of other processing factors like RNA-binding motif protein Rbm19 in mice disrupts embryonic development in a manner dependent on p53-induced apoptosis (Zhang et al. 2008). In addition, depletion of Wrd36 in zebrafish perturbs $18 \mathrm{~S}$ rRNA processing to induce p53-dependent activity (Skarie and Link 2008). The weight of evidence supports the notion that insufficient yields of mature rRNA, or accumulation of unprocessed intermediates, may trigger a nucleolar stress response under surveillance by the ribosomal protein-MDM2-p53 axis.

The evidence for nucleolar stress mediating p53 activation is supported by several key events encompassing ribosome biogenesis. Whether it be modulation of rRNA transcription and processing, or ribosome assembly, it is clear that maintaining precision tuning of ribosome synthesis is essential for cell homeostasis. Several modes of action have been postulated for ribosomal protein-MDM2-p53 surveillance of protein synthesis. For instance, a reduction in the pool of ribosomal proteins or rRNA-processing factors may retard the rate of ribosome synthesis, leaving a larger pool of ribonucleoprotein intermediates or preprocessed rRNA that could disrupt the natural order of the nucleolus. Ribosomal proteins are then available to bind MDM2 and stabilize p53. Likewise, attenuation of nascent rRNA synthesis could also leave an excess of ribosomal proteins free to bind MDM2 (Zhang and Lu 2009). Last, nucleolar integrity may still be maintained and instead rely on more specific signaling compo- 
C. Deisenroth et al.

nents to transduce signals to p53 in the event of disruptions to ribosome biogenesis (Fumagalli et al. 2009). Despite the current absence of complete mechanistic clarity, progress on these fronts may lead to novel strategies for therapeutic applications.

\section{CHARACTERIZATION OF RIBOSOMAL PROTEIN-MDM2 INTERACTIONS}

The earliest identification of ribosomal protein binding to MDM2 can be traced back to some of the original reports identifying MDM2 itself. MDM2 was first identified in the 3T3DM tumorigenic mouse cell line, in which amplification of the MDM2 gene was thought to directly contribute to the transforming potential of the cell (Fakharzadeh et al. 1991). Further characterization of MDM2 using a number of rat and mouse cell lines suggested that MDM2 binding inhibits p53 transactivation (Momand et al. 1992). Continued studies in 3T3DM cells have shown that immunoprecipitation of MDM2 consistently pulls down p53, as well as a $34-\mathrm{kDa}$ protein that corresponded to ribosomal protein L5 (RPL5). Northern blot analysis of the immunoprecipitated MDM2 further revealed that MDM2-p53 complexes also bind with 5S rRNA (Marechal et al. 1994). Initially, the ubiquitous expression of ribosomal proteins and rRNAs led to their being labeled as contaminants in many early experiments delaying the study of the ribosomal protein-MDM2 interaction. It would then take decades to fully realize the implications of the interaction.

Similar to RPL5, RPL11 also binds MDM2 in HeLa cells, and this association was independent of RNA as shown by RNAse A treatment in U2OS cells. Moreover, RPL11 was shown to stabilize $\mathrm{p} 53$ by binding the central acidic domain of MDM2 independent of RPL5, and RPL11MDM2 association was increased after treatment with low levels of actinomycin D (Zhang et al. 2003a). This study suggested that RPL11, not RPL5, is the major facilitator of ribosomalprotein-mediated p53 stabilization. Further investigations have shown that simultaneous depletion of large and small subunit proteins results in an even greater stabilization of p53 than single subunit inhibition, suggesting that the mechanisms behind small subunit inhibition and large subunit-inhibition-mediated p53 stabilization are independent. The p53 stabilization mediated by inhibition of both ribosomal subunit assemblies preferentially results in a cell-cycle arrest phenotype, rather than the apoptotic response that is expected, during high levels of p53 expression through a currently unknown mechanism (Fumagalli et al. 2012). Numerous studies have implicated RPL5 and RPL11 as central mediators of the ribosomal protein-MDM2-p53 pathway; however, RPS3 (Yadavilli et al. 2009), RPS7 (Chen et al. 2007), RPS14 (Zhou et al. 2013), RPS15 (Daftuar et al. 2013), RPS20 (Daftuar et al. 2013), RPS25 (Zhang et al. 2013), RPS26 (Cui et al. 2014), RPS27 (Xiong et al. 2011), RPL23 (Jin et al. 2004), RPL26 (Zhang et al. 2010), and RPL37 (Daftuar et al. 2013) have all been shown to bind MDM2 as well. The independent functions and contributions, if any, are just in the early stages of exploration.

As mentioned, 5S rRNA was immunoprecipitated with MDM2 as early as 20 years ago (Marechal et al. 1994), but the role of 5S rRNA and the $5 \mathrm{~S}$ ribonucleoprotein (RNP) in the MDM2-p53 pathway has only recently been investigated. RPL5 and RPL11 association with MDM2 and subsequent p53 activation was shown to require $5 \mathrm{~S}$ rRNA in a recent study in which siRNA against TFIIIA, a component of the RNA POLIII transcription complex, was used to deplete U2OS cells of 5S rRNA (Donati et al. 2013). This finding suggests that 5 S rRNA plays a more significant role in RPL5 and RPL11 association with MDM2 than previous studies have suggested. Additionally, RPL5, RPL11, and 5S rRNA are all required for maintenance of p53 stability in both stressed and unstressed conditions. The association of 5S rRNA was further shown to require RPL5 and RPL11 association as MDM2 C305F, a point mutant that abrogates RPL5 and RPL11 association, does not bind 5S rRNA (Sloan et al. 2013). Interestingly, the 5S RNP complex was also shown to be necessary for $\mathrm{p} 14^{\mathrm{ARF}}$ stabilization of $\mathrm{p} 53$, which supports previous studies in which RPL11 was deemed necessary for $\mathrm{p} 14^{\mathrm{ARF}}$-mediated $\mathrm{p} 53$ activation 
(Dai et al. 2012; Sloan et al. 2013). The crystal structure for the yeast ribosome illustrates a central location for the RPL5/RPL11/5S RNP complex at the interface of the $60 \mathrm{~S}$ and $40 \mathrm{~S}$ subunits. This is a key position necessary for ribosome ratcheting, a shift in conformational state that is required for proper translational function of the ribosome (Ben-Shem et al. 2011). The essential nature for all three components of the 5S RNP complex to bind to MDM2 could suggest a mechanism, whereby p53 continuously monitors ribosomal translation fidelity. Given the central location of the complex at the subunit interface, it may be the most likely first responder to ribosomal stress. Therefore, the $\mathrm{RP}-\mathrm{MDM} 2$ pathway may receive stress signals from oncogenic overproduction of ribosomal proteins, liberation of ribosomal proteins from the nucleolus, and the release of ribonucleoproteins from disassembly of mature ribosomes (Fig. 2).

A recent study using the MDM2 C305F knockin mice showed that RPL5 and RPL11 binding to MDM2 was dispensable for p53-mediated DNA-damage response, but that p53 was not activated in response to ribosomal stress induced by actinomycin D, MPA, and 5-FU. Be- cause the oncogene c-Myc increases ribosome biogenesis via activation of all three RNA polymerases (Gomez-Roman et al. 2003; Grandori et al. 2005; Rahl et al. 2010), the C305F mouse model was then combined with an E $\mu$-Mycdriven lymphoma model to understand the role of the ribosomal protein-MDM2-p53 pathway in tumorigenesis. This study showed that the ribosomal protein-MDM2-p53 pathway acts in an independent, but relevant manner, with the tumor suppressor ARF because oncogenesis is increased in the absence of RPL5- and RPL11-mediated p53 activation (Macias et al. 2010).

Ribosomal proteins have not been shown to bind directly to murine double minute 4 (MDM4; aka MDMX), but a recent study suggests that RPL11 association with MDM2 also modulates MDMX stability to promote p53 activation. The additional layer of regulation of MDMX is necessary during ribosomal stress because neither MDMX nor p53 is phosphorylated to inhibit protein-protein interactions that inhibit p53 transactivation. In support of this observation, MDMX overexpression was sufficient to mitigate ribosomal stress induced by 5-FU and actinomycin D (Gilkes et al. 2006).

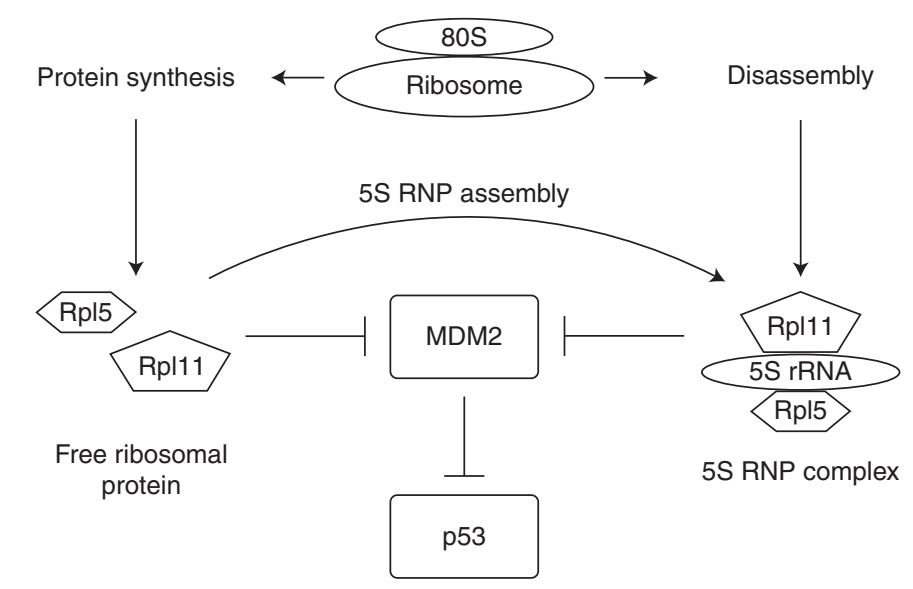

Figure 2. Possible mechanisms of ribosomal proteins L5 and L11 signaling to MDM2. Ribosomal proteins L5 and L11 appear to play integral roles in signaling ribosomal functions to p53. Free RPL5 or RPL11 may be released from the nucleolus during nucleolar stress, or act as sentinels for overproduction of ribosomal proteins during protein synthesis. By binding independently to MDM2, or as a component of the $5 \mathrm{~S}$ ribonucleoprotein (RNP) complex, MDM2 is inhibited to stabilize p53. Conversely, p53 may also monitor fidelity of protein synthesis or rate of ribosome disassembly by enabling the 5S RNP complex to inhibit MDM2 and promote p53 transactivation. 
C. Deisenroth et al.

\section{RIBOSOME BIOGENESIS AND DISEASE}

Mutations in ribosomal proteins, or proteins associated with ribosome biogenesis, show a number of phenotypes and developmental deficiencies classified as ribosomopathies. Generally speaking, most conditions arising from ribosomopathies cannot simply be explained by decreased protein synthesis. DiamondBlackfan anemia (DBA), one of the earliest and most well studied of the ribosomopathies, is characterized by decreased viability of erythroid progenitor cells in the bone marrow that often presents early in infancy. Genetic mapping of DBA patients targeting a specific region in chromosome 19 revealed that RPS19 is encoded in this region; thus, it is reasonable to observe that $25 \%$ of DBA patients show RPS19 deletions (Draptchinskaia et al. 1999). In addition to anemia associated with erythroid progenitor defects, DBA patients commonly show diverse physical malformations. Mutations in RPS7, RPS10, RPS17, RPS24, RPS26, RPL5, RPL11, and RPL35A have also been associated with the manifestation of DBA, and these mutations predominantly appear to impair ribosomal protein stability or localization (Boria et al. 2010). Cells harboring mutations in RPL11 show delayed differentiation and increased apoptosis compared with cells harboring the more common RPS19 mutations. Decreased cell proliferation and increased p53 activity were also observed in response to shRNA knockdown of RPL11 and RPS19, implicating excessive p53 activity as a potential contributor to DBA. Consistent with this notion, shRNA against p53 partially rescues the DBA phenotype (Moniz et al. 2012). A recent study in human TF1 cells suggested that, independent of p53 activation, depleted expression of RPS19, RPL5, and RPL11 caused cells to be more susceptible to oxidative stress, leading to decreased cell proliferation (Aspesi et al. 2014). A recent study using the North American DBA patient registry revealed that DBA patients show a higher likelihood of developing various forms of cancer than the general population, suggesting a correlation between altered ribosome biogenesis and cancer (Vlachos et al. 2012).
$5 \mathrm{q}$-syndrome is another well-studied ribosomopathy characterized by the World Health Organization as a myelodysplastic syndrome with cytogenic abnormality/deletion of chromosome 5 between q21 and q32. 5q-syndrome presents with macrocytic anemia, increased platelet counts, and megakaryocytes; yet, the number of erythroblasts in the bone marrow and blood is $<5 \%$ of normal (Vardiman et al. 2002). The cytogenic abnormal region on chromosome 5 was observed to contain 40 genes, but only shRNA-mediated depletion of RPS14 recapitulated the $5 \mathrm{q}$-syndrome phenotype in haemotopoietic progenitor cells. Lentiviral expression of RPS14 in CD34 ${ }^{+}$cells rescues the differentiation of erythroid progenitor cells from $5 \mathrm{q}$-syndrome patients. The depletion of RPS14 caused an accumulation of $30 \mathrm{~S}$ prerRNA, a hallmark of ribosomal stress, and patients show significant response to lenalidomide through an unknown mechanism that may involve p53 (Ebert et al. 2008). Furthermore, 5qsyndrome patients show a higher likelihood of developing acute myeloid leukemia, strengthening the connection between the ribosomopathy and the tumor suppressor p53 (Van den Berghe et al. 1985; Ebert et al. 2008).

Treacher-Collins syndrome (TCS) is caused by mutations that result in early termination of the TCOF gene, which encodes the treacle protein (Wise et al. 1997; Valdez et al. 2004). Treacle has been shown to colocalize with UBF, a signaling node used by tumor suppressors to regulate ribosome biogenesis. Preliminary studies using siRNA against treacle in HeLa cells and $\mathrm{TCOF}^{+/-}$MEF cells show that treacle expression is necessary for rRNA production (Valdez et al. 2004). TCS patients show varying degrees of craniofacial disorder because of increased neuroepithelial apoptosis during early development. This phenotype is recapitulated in $\mathrm{TCOF}^{+/-}$mice, and the observed apoptosis in neuroepithelial cells can be blocked through injections of the p53 inhibitor pfithrin- $\alpha$. Furthermore, knockout of p53 in $\mathrm{TCOF}^{+/-}$mice rescues the craniofacial phenotype suggesting that TCS is p53 dependent (Jones et al. 2008).

Shwachman-Diamond syndrome (SDS) patients show a diverse array of phenotypes in- 
cluding pancreatic insufficiency, short stature, anemia, skeletal abnormalities, endocrine abnormalities, and defects in T- and B-cell function (Shimamura 2006). SDS patients commonly show mutations in the SBDS gene, which is involved with the maturation and export of $60 \mathrm{~S}$ subunit, that result in early termination and truncated protein production (Ganapathi et al. 2007). RNAi-mediated knockdown of SBDS in human fibroblasts and SDS patient samples both display decreased rRNA synthesis, in addition to increased Fas-mediated apoptosis (Ganapathi et al. 2007; Rujkijyanont et al. 2008). As Fas is a known p53 target gene (Owen-Schaub et al. 1995), SDS phenotype is likely to be driven by ribosomal stress activation of p53.

Cartilage hair hypoplasia $(\mathrm{CHH})$ is a ribosomopathy associated with short-limbed dwarfism and immune cell deficiencies. $\mathrm{CHH}$ patients commonly show mutations in the $R M R P$ gene that encodes a ribonucleoprotein responsible for pre-rRNA cleavage and maturation (Ridanpaa et al. 2001). Analysis of the $\mathrm{CHH}$ patient database in Finland revealed that $\mathrm{CHH}$ patients show a higher likelihood of developing cancer at an early age with non-Hodgkin's lymphoma and basal cell carcinoma being the most commonly diagnosed forms of cancer (Taskinen et al. 2008).

\section{PERSPECTIVE}

The evolution of our understanding of ribosomal proteins from static building blocks of the ribosome to highly integrated sensors of p53 function and cell-cycle surveillance has achieved a tremendous rate of growth over the past several decades. Like many serendipitous discoveries in science, the observation that ribosomal proteins could bind to MDM2 was originally disregarded as having nonbiological significance. Through the efforts of multiple laboratories, ribosomal proteins are now appreciated as critical regulators of MDM2 - p53 surveillance activity. More surprising, and likely unforeseen, were the implications of ribosomal proteins in disease states ranging from developmental anomalies to cancer. Renewed appreciation and interest in studying ribosome biology is now paving the way for a deeper biological understanding of not only the fundamental coupling of cell growth with division, but also new areas for therapeutic interventions of the ribosomal protein-MDM2-p53 axis.

Ribosome protein expression and ribosome biogenesis are commonly misregulated in cancer. This lends the possibility of profiling tumor subtypes by identifying key biomarkers for diagnostic and drug discovery applications. For example, expression of RPS3, RPS6, RPS8, RPS12, RPL5, RPS11, RPS18, RPS24, RPL7, RPL13a, RPL18, RPL28, and RPL32 are all increased in colorectal cancer cells compared with normal cells (Pogue-Geile et al. 1991; Kasai et al. 2003). Other ribosomal proteins such as RPS8, RPL12, RPL23A, RPL27, and RPL30 are highly expressed in hepatocellular carcinoma cell lines (Kondoh et al. 2001). RPL19 specifically has been shown to be overexpressed in both ERB2 positive breast cancer and prostate cancer (Henry et al. 1993; Bee et al. 2006), whereas RPL15 is overexpressed in esophageal cancer (Wang et al. 2001). The differential expression profiles may function as lineage tracers to distinguish these tissue-specific cancer subtypes. More so, correlating MDM2 and p53 status in these primary tumor types may provide some correlation to tumor pathogenesis as it relates to ribosomal protein-MDM2-p53 signaling. The regulation of ribosomal protein expression and rRNA synthesis by tumor suppressors and oncogenes, along with the numerous studies correlating ribosomal protein expression with tumor growth, suggests that ribosome biogenesis is a central cellular process that when improperly regulated is a facilitator of tumorigenesis.

Regulation of metabolic homeostasis has been proposed as a key function for normal p53 activity (Deisenroth and Zhang 2011). The majority of studies on the ribosomal proteinMDM2-p53 pathway have used exogenous and tagged expression of ribosomal proteins and MDM2 in in vitro systems to understand the protein-protein interactions responsible for regulation of p53. More recently, MDM2 C305F mutant mice have facilitated in vivo studies on the role of the ribosomal proteinMDM2-p53 pathway in nutrient homeostasis. 
C. Deisenroth et al.

MDM2 C305F mice show normal life span and weight gain in the absence of oncogenic stress. Surprisingly, C305F mice show altered metabolic balance both under normal and starved conditions. These include higher rates of glycolysis compared with wild-type mice during normal feeding and decreased lipid catabolism in the liver during starvation. A novel p53 target gene, malonyl-CoA decarboxylase, was specifically up-regulated during starvation in wild-type mice to facilitate lipid catabolism and oxidative phosphorylation (Liu et al. 2014). This study suggests that the ribosomal protein-MDM2p53 pathway plays a significant role in maintaining nutrient homeostasis in both fed and nutrient-deprived conditions. The intrinsic connections between p53 and ribosomal biogenesis are necessary to facilitate cell survival in the face of varied nutrient availability as ribosome biogenesis is an energetically demanding process for mammalian cells. This insight into p53-regulated metabolic balance opens up a new area for study that could yield new approaches to treatment of metabolic diseases.

The identification of ribosomal proteins as modulators of MDM2 - p53 surveillance activity has enabled observations of their extraribosomal functions in a diverse array of signaling processes. From cell-cycle control, to DNA repair, cell growth, and energy metabolism, it is becoming clearer that there may be distinct ribosomal protein-MDM2-p53 systems monitoring multiple aspects of gene expression and protein synthesis. Future research endeavors will continue to describe the biological mechanisms and processes that ribosomal proteins are involved in, as well as the dependent contribution of individual proteins to more discrete cellular functions. As we move outside the scope of basic science, there are distinct areas for the ribosome biology to translate to novel target identification for drug development in cancer and ribosome-based disease.

\section{ACKNOWLEDGMENTS}

We thank Lee Graves, Jeffery MacDonald, Adrienne Cox, Yong Liu, Aiwen Jin, and Laura Tollini for their helpful advice and technical assistance. This research was supported in part by grants from the National Institutes of Health (CA127770, CA100302, CA155235, and CA167637) and from the NSFC and Jiangsu Center for the Collaboration and Innovation of Cancer Biotherapy to Y.Z. This research is also supported by funding from the American Chemistry Council Long Range Research Initiative to C.D. We apologize for not being able to cite all of the relevant papers because of limited space.

\section{REFERENCES}

Anderson SJ, Lauritsen JP, Hartman MG, Foushee AM, Lefebvre JM, Shinton SA, Gerhardt B, Hardy RR, Oravecz T, Wiest DL. 2007. Ablation of ribosomal protein L22 selectively impairs $\alpha \beta \mathrm{T}$ cell development by activation of a p53-dependent checkpoint. Immunity 26: 759-772.

Aspesi A, Pavesi E, Robotti E, Crescitelli R, Boria I, Avondo F, Moniz H, Da Costa L, Mohandas N, Roncaglia P, et al 2014. Dissecting the transcriptional phenotype of ribosomal protein deficiency: Implications for DiamondBlackfan anemia. Gene 545: 282-289.

Ayrault O, Andrique L, Fauvin D, Eymin B, Gazzeri S, Seite P. 2006. Human tumor suppressor p $14^{\mathrm{ARF}}$ negatively regulates rRNA transcription and inhibits UBF1 transcription factor phosphorylation. Oncogene 25: 7577-7586.

Bee A, Ke Y, Forootan S, Lin K, Beesley C, Forrest SE, Foster CS. 2006. Ribosomal protein 119 is a prognostic marker for human prostate cancer. Clin Cancer Res 12: 20612065 .

Ben-Shem A, Jenner L, Yusupova G, Yusupov M. 2011. Crystal structure of the eukaryotic ribosome. Science 330: 1203-1209.

Berghofer-Hochheimer Y, Zurek C, Wolfl S, Hemmerich P, Munder T. 1998. L7 protein is a coregulator of vitamin D receptor-retinoid $\mathrm{X}$ receptor-mediated transactivation. J Cell Biochem 69: 1-12.

Bhat KP, Itahana K, Jin A, Zhang Y. 2004. Essential role of ribosomal protein L11 in mediating growth inhibitioninduced p53 activation. EMBO J 23: 2402-2412.

Blattner C, Sparks A, Lane D. 1999. Transcription factor E2F-1 is upregulated in response to DNA damage in a manner analogous to that of p53. Mol Cell Biol 19: 37043713.

Boisvert FM, van Koningsbruggen S, Navascues J, Lamond AI. 2007. The multifunctional nucleolus. Nat Rev Mol Cell Biol 8: 574-585.

Boria I, Garelli E, Gazda HT, Aspesi A, Quarello P, Pavesi E, Ferrante D, Meerpohl JJ, Kartal M, Da Costa L, et al. 2010 The ribosomal basis of Diamond-Blackfan anemia: $\mathrm{Mu}-$ tation and database update. Hum Mutat 31: 1269-1279.

Chen D, Zhang Z, Li M, Wang W, Li Y, Rayburn ER, Hill DL, Wang H, Zhang R. 2007. Ribosomal protein S7 as a novel modulator of p53-MDM2 interaction: Binding to MDM2, stabilization of p53 protein, and activation of p53 function. Oncogene 26: 5029-5037. 
Cui K, Coutts M, Stahl J, Sytkowski AJ. 2000. Novel interaction between the transcription factor $\mathrm{CHOP}$ (GADD153) and the ribosomal protein FTE/S3a modulates erythropoiesis. J Biol Chem 275: 7591-7596.

Cui D, Li L, Lou H, Sun H, Ngai SM, Shao G, Tang J. 2014. The ribosomal protein S26 regulates p53 activity in response to DNA damage. Oncogene 33: 2225-2235.

Daftuar L, Zhu Y, Jacq X, Prives C. 2013. Ribosomal proteins RPL37, RPS15 and RPS20 regulate the Mdm2-p53MdmX network. PLoS ONE 8: e68667.

Dai MS, Lu H. 2004. Inhibition of MDM2-mediated p53 ubiquitination and degradation by ribosomal protein L5. J Biol Chem 279: 44475-44482.

Dai MS, Zeng SX, Jin Y, Sun XX, David L, Lu H. 2004 Ribosomal protein L23 activates p53 by inhibiting MDM2 function in response to ribosomal perturbation but not to translation inhibition. Mol Cell Biol 24: 76547668.

Dai MS, Shi D, Jin Y, Sun XX, Zhang Y, Grossman SR, Lu H. 2006. Regulation of the MDM2-p53 pathway by ribosomal protein L11 involves a post-ubiquitination mechanism. J Biol Chem 281: 24304-24313.

Dai MS, Arnold H, Sun XX, Sears R, Lu H. 2007. Inhibition of c-Myc activity by ribosomal protein L11. EMBO J 26: $3332-3345$.

Dai MS, Challagundla KB, Sun XX, Palam LR, Zeng SX, Wek RC, Lu H. 2012. Physical and functional interaction between ribosomal protein $\mathrm{L} 11$ and the tumor suppressor ARF. J Biol Chem 287: 17120-17129.

Deisenroth C, Zhang Y. 2011. The ribosomal proteinMdm2-p53 pathway and energy metabolism: Bridging the gap between feast and famine. Genes Cancer 2: 392 403.

Donati G, Peddigari S, Mercer CA, Thomas G. 2013. 5S ribosomal RNA is an essential component of a nascent ribosomal precursor complex that regulates the $\mathrm{Hdm} 2-$ p53 checkpoint. Cell Rep 4: 87-98.

Draptchinskaia N, Gustavsson P, Andersson B, Pettersson M, Willig TN, Dianzani I, Ball S, Tchernia G, Klar J, Matsson H, et al. 1999. The gene encoding ribosomal protein S19 is mutated in Diamond-Blackfan anaemia. Nat Genet 21: 169-175.

Duan J, Ba Q, Wang Z, Hao M, Li X, Hu P, Zhang D, Zhang R, Wang H. 2011. Knockdown of ribosomal protein S7 causes developmental abnormalities via p53 dependent and independent pathways in zebrafish. Int J Biochem Cell Biol 43: 1218-1227.

Ebert BL, Pretz J, Bosco J, Chang CY, Tamayo P, Galili N, Raza A, Root DE, Attar E, Ellis SR, et al. 2008. Identification of RPS14 as a $5 \mathrm{q}^{-}$syndrome gene by RNA interference screen. Nature 451: 335-339.

Fakharzadeh SS, Trusko SP, George DL. 1991. Tumorigenic potential associated with enhanced expression of a gene that is amplified in a mouse tumor cell line. EMBO J 10: $1565-1569$.

Fumagalli S, Di Cara A, Neb-Gulati A, Natt F, Schwemberger S, Hall J, Babcock GF, Bernardi R, Pandolfi PP, Thomas G. 2009. Absence of nucleolar disruption after impairment of $40 \mathrm{~S}$ ribosome biogenesis reveals an rpL11-translationdependent mechanism of p53 induction. Nat Cell Biol 11: 501-508.
Fumagalli S, Ivanenkov VV, Teng T, Thomas G. 2012. Suprainduction of p53 by disruption of $40 \mathrm{~S}$ and $60 \mathrm{~S}$ ribosome biogenesis leads to the activation of a novel $\mathrm{G}_{2} / \mathrm{M}$ checkpoint. Genes Dev 26: 1028-1040.

Ganapathi KA, Austin KM, Lee CS, Dias A, Malsch MM, Reed R, Shimamura A. 2007. The human ShwachmanDiamond syndrome protein, SBDS, associates with ribosomal RNA. Blood 110: 1458-1465.

Gilkes DM, Chen L, Chen J. 2006. MDMX regulation of p53 response to ribosomal stress. EMBO J 25: 5614-5625.

Gomez-Roman N, Grandori C, Eisenman RN, White RJ. 2003. Direct activation of RNA polymerase III transcription by c-Myc. Nature 421: 290-294.

Grandori C, Gomez-Roman N, Felton-Edkins ZA, Ngouenet C, Galloway DA, Eisenman RN, White RJ. 2005. cMyc binds to human ribosomal DNA and stimulates transcription of rRNA genes by RNA polymerase I. Nat Cell Biol 7: 311-318.

Gray JP, Davis JW, Gopinathan L, Leas TL, Nugent CA, Vanden Heuvel JP. 2006. The ribosomal protein rpL11 associates with and inhibits the transcriptional activity of peroxisome proliferator-activated receptor- $\alpha$. Toxicol Sci 89: 535-546.

Hannan KM, Hannan RD, Smith SD, Jefferson LS, Lun M, Rothblum LI. 2000. Rb and p130 regulate RNA polymerase I transcription: $\mathrm{Rb}$ disrupts the interaction between UBF and SL-1. Oncogene 19: 4988-4999.

Hegde V, Wang M, Deutsch WA. 2004a. Characterization of human ribosomal protein S3 binding to 7,8-dihydro-8oxoguanine and abasic sites by surface plasmon resonance. DNA Repair (Amst) 3: 121-126.

Hegde V, Wang M, Deutsch WA. 2004b. Human ribosomal protein S3 interacts with DNA base excision repair proteins hAPE/Ref-1 and hOGG1. Biochemistry 43: 14211 14217.

Henry JL, Coggin DL, King CR. 1993. High-level expression of the ribosomal protein L19 in human breast tumors that overexpress erbB-2. Cancer Res 53: 1403-1408.

Holzel M, Rohrmoser M, Schlee M, Grimm T, Harasim T, Malamoussi A, Gruber-Eber A, Kremmer E, Hiddemann W, Bornkamm GW, et al. 2005. Mammalian WDR12 is a novel member of the Pes1-Bopl complex and is required for ribosome biogenesis and cell proliferation. J Cell Biol 170: $367-378$.

Huang M, Ji Y, Itahana K, Zhang Y, Mitchell B. 2008. Guanine nucleotide depletion inhibits pre-ribosomal RNA synthesis and causes nucleolar disruption. Leuk Res 32: $131-141$.

Jin A, Itahana K, O'Keefe K, Zhang Y. 2004. Inhibition of HDM2 and activation of $\mathrm{p} 53$ by ribosomal protein L23. Mol Cell Biol 24: 7669-7680.

Jones NC, Lynn ML, Gaudenz K, Sakai D, Aoto K, Rey JP, Glynn EF, Ellington L, Du C, Dixon J, et al. 2008. Prevention of the neurocristopathy Treacher-Collins syndrome through inhibition of p53 function. Nat Med 14: 125133.

Kasai H, Nadano D, Hidaka E, Higuchi K, Kawakubo M, Sato TA, Nakayama J. 2003. Differential expression of ribosomal proteins in human normal and neoplastic colorectum. J Histochem Cytochem 51: 567-574. 
C. Deisenroth et al.

Kondoh N, Shuda M, Tanaka K, Wakatsuki T, Hada A, Yamamoto M. 2001. Enhanced expression of S8, L12, L23a, L27 and L30 ribosomal protein mRNAs in human hepatocellular carcinoma. Anticancer Res 21: 2429-2433.

Lindström MS. 2009. Emerging functions of ribosomal proteins in gene-specific transcription and translation. Biochem Biophys Res Commun 379: 167-170.

Lindström MS, Zhang Y. 2008. Ribosomal protein S9 is a novel B23/NPM-binding protein required for normal cell proliferation. J Biol Chem 283: 15568-15576.

Liu JJ, Huang BH, Zhang J, Carson DD, Hooi SC. 2006 Repression of HIP/RPL29 expression induces differentiation in colon cancer cells. J Cell Physiol 207: 287-292.

Liu F, Li Y, Yu Y, Fu S, Li P. 2007. Cloning of novel tumor metastasis-related genes from the highly metastatic human lung adenocarcinoma cell line Anip973. J Genet Genomics 34: 189-195.

Liu Y, He Y, Jin A, Tikunov AP, Zhou L, Tollini LA, Leslie P, Kim TH, Li LO, Coleman RA, et al. 2014. Ribosomal protein-Mdm2-p53 pathway coordinates nutrient stress with lipid metabolism by regulating MCD and promoting fatty acid oxidation. Proc Natl Acad Sci 111: E2414-E2422.

Lohrum MA, Ludwig RL, Kubbutat MH, Hanlon M, Vousden KH. 2003. Regulation of HDM2 activity by the ribosomal protein L11. Cancer Cell 3: 577-587.

Longley DB, Harkin DP, Johnston PG. 2003. 5-fluorouracil: Mechanisms of action and clinical strategies. Nat Rev Cancer 3: 330-338.

Macias E, Jin A, Deisenroth C, Bhat K, Mao H, Lindström MS, Zhang Y. 2010. An ARF-independent c-MYC-activated tumor suppression pathway mediated by ribosomal protein-Mdm2 interaction. Cancer Cell 18: 231-243.

Malygin AA, Parakhnevitch NM, Ivanov AV, Eperon IC, Karpova GG. 2007. Human ribosomal protein S13 regulates expression of its own gene at the splicing step by a feedback mechanism. Nucleic Acids Res 35: 6414-6423.

Marechal V, Elenbaas B, Piette J, Nicolas JC, Levine AJ. 1994 The ribosomal L5 protein is associated with $\mathrm{mdm}-2$ and mdm-2-p53 complexes. Mol Cell Biol 14: 7414-7420.

Mazumder B, Sampath P, Seshadri V, Maitra RK, DiCorleto PE, Fox PL. 2003. Regulated release of L13a from the 60S ribosomal subunit as a mechanism of transcript-specific translational control. Cell 115: 187-198.

McDonald JM, Pelloski CE, Ledoux A, Sun M, Raso G Komaki R, Wistuba II, Bekele BN, Aldape K. 2008. Elevated phospho-S6 expression is associated with metastasis in adenocarcinoma of the lung. Clin Cancer Res 14: 7832-7837.

McGowan KA, Li JZ, Park CY, Beaudry V, Tabor HK, Sabnis AJ, Zhang W, Fuchs H, de Angelis MH, Myers RM, et al. 2008. Ribosomal mutations cause p53-mediated dark skin and pleiotropic effects. Nat Genet 40: 963-970.

Momand J, Zambetti GP, Olson DC, George D, Levine AJ. 1992. The $m d m-2$ oncogene product forms a complex with the p53 protein and inhibits p53-mediated transactivation. Cell 69: 1237-1245.

Moniz H, Gastou M, Leblanc T, Hurtaud C, Cretien A, Lecluse Y, Raslova H, Larghero J, Croisille L, Faubladier M, et al. 2012. Primary hematopoietic cells from DBA patients with mutations in RPL11 and RPS19 genes ex- hibit distinct erythroid phenotype in vitro. Cell Death Dis 3: e356.

Neumann F, Hemmerich P, von Mikecz A, Peter HH, Krawinkel U. 1995. Human ribosomal protein L7 inhibits cell-free translation in reticulocyte lysates and affects the expression of nuclear proteins upon stable transfection into Jurkat T-lymphoma cells. Nucleic Acids Res 23: 195-202.

Oliver ER, Saunders TL, Tarle SA, Glaser T. 2004. Ribosomal protein L24 defect in belly spot and tail (Bst), a mouse Minute. Development 131: 3907-3920.

Owen-Schaub LB, Zhang W, Cusack JC, Angelo LS, Santee SM, Fujiwara T, Roth JA, Deisseroth AB, Zhang WW, Kruzel E, et al. 1995. Wild-type human p53 and a temperature-sensitive mutant induce Fas/APO-1 expression. Mol Cell Biol 15: 3032-3040.

Panic L, Tamarut S, Sticker-Jantscheff M, Barkic M, Solter D, Uzelac M, Grabusic K, Volarevic S. 2006. Ribosomal protein $\mathrm{S} 6$ gene haploinsufficiency is associated with activation of a p53-dependent checkpoint during gastrulation. Mol Cell Biol 26: 8880-8891.

Parlato R, Kreiner G, Erdmann G, Rieker C, Stotz S, Savenkova E, Berger S, Grummt I, Schutz G. 2008. Activation of an endogenous suicide response after perturbation of rRNA synthesis leads to neurodegeneration in mice. J Neurosci 28: 12759-12764.

Perry RP. 1963. Selective effects of actinomycin D on the intracellular distribution of RNA synthesis in tissue culture cells. Exp Cell Res 29: 400-406.

Pestov DG, Strezoska Z, Lau LF. 2001. Evidence of p53-dependent cross-talk between ribosome biogenesis and the cell cycle: Effects of nucleolar protein Bopl on $\mathrm{G}_{1} / \mathrm{S}$ transition. Mol Cell Biol 21: 4246-4255.

Pogue-Geile K, Geiser JR, Shu M, Miller C, Wool IG, Meisler AI, Pipas JM. 1991. Ribosomal protein genes are overexpressed in colorectal cancer: Isolation of a cDNA clone encoding the human S3 ribosomal protein. Mol Cell Biol 11: 3842-3849.

Rahl PB, Lin CY, Seila AC, Flynn RA, McCuine S, Burge CB, Sharp PA, Young RA. 2010. c-Myc regulates transcriptional pause release. Cell 141: 432-445.

Ridanpaa M, van Eenennaam H, Pelin K, Chadwick R, Johnson C, Yuan B, vanVenrooij W, Pruijn G, Salmela R, Rockas S, et al. 2001. Mutations in the RNA component of RNase MRP cause a pleiotropic human disease, cartilage-hair hypoplasia. Cell 104: 195-203.

Rubbi CP, Milner J. 2003. Disruption of the nucleolus mediates stabilization of $\mathrm{p} 53$ in response to DNA damage and other stresses. EMBO J 22: 6068-6077.

Rujkijyanont P, Watanabe K, Ambekar C, Wang H, Schimmer A, Beyene J, Dror Y. 2008. SBDS-deficient cells undergo accelerated apoptosis through the Fas-pathway. Haematologica 93: 363-371.

Ruvinsky I, Meyuhas O. 2006. Ribosomal protein S6 phosphorylation: From protein synthesis to cell size. Trends Biochem Sci 5: 5.

Shimamura A. 2006. Shwachman-Diamond syndrome. Semin Hematol 43: 178-188.

Skarie JM, Link BA. 2008. The primary open-angle glaucoma gene WDR36 functions in ribosomal RNA processing 
and interacts with the p53 stress-response pathway. Hum Mol Genet 17: 2474-2485.

Sloan KE, Bohnsack MT, Watkins NJ. 2013. The 5S RNP couples p53 homeostasis to ribosome biogenesis and nucleolar stress. Cell Rep 5: 237-247.

Sobell HM, Jain SC, Sakore TD, Nordman CE. 1971. Stereochemistry of actinomycin-DNA binding. Nat New Biol 231: $200-205$

Strezoska Z, Pestov DG, Lau LF. 2002. Functional inactivation of the mouse nucleolar protein Bop1 inhibits multiple steps in pre-rRNA processing and blocks cell cycle progression. J Biol Chem 277: 29617-29625.

Sugimoto M, Kuo ML, Roussel MF, Sherr CJ. 2003. Nucleolar Arf tumor suppressor inhibits ribosomal RNA processing. Mol Cell 11: 415-424.

Sulic S, Panic L, Barkic M, Mercep M, Uzelac M, Volarevic S. 2005. Inactivation of $S 6$ ribosomal protein gene in $T$ lymphocytes activates a p53-dependent checkpoint response. Genes Dev 19: 3070-3082.

Sun XX, Dai MS, Lu H. 2007. 5-fluorouracil activation of p53 involves an MDM2-ribosomal protein interaction. J Biol Chem 282: 8052-8059.

Takagi M, Absalon MJ, McLure KG, Kastan MB. 2005. Regulation of p53 translation and induction after DNA damage by ribosomal protein L26 and nucleolin. Cell 123: $49-63$.

Tang Q, Rice DS, Goldowitz D. 1999. Disrupted retinal development in the embryonic belly spot and tail mutant mouse. Dev Biol 207: 239-255.

Tasheva ES, Roufa DJ. 1995. Regulation of human RPS14 transcription by intronic antisense RNAs and ribosomal protein S14. Genes Dev 9: 304-316.

Taskinen M, Ranki A, Pukkala E, Jeskanen L, Kaitila I, Makitie O. 2008. Extended follow-up of the Finnish cartilage-hair hypoplasia cohort confirms high incidence of non-Hodgkin lymphoma and basal cell carcinoma. Am J Med Genet A 146A: 2370-2375.

Tschochner H, Hurt E. 2003. Pre-ribosomes on the road from the nucleolus to the cytoplasm. Trends Cell Biol 13: $255-263$.

Uechi T, Nakajima Y, Nakao A, Torihara H, Chakraborty A, Inoue K, Kenmochi N. 2006. Ribosomal protein gene knockdown causes developmental defects in zebrafish. PLOS ONE 1: e37.

Uechi T, Nakajima Y, Chakraborty A, Torihara H, Higa S, Kenmochi N. 2008. Deficiency of ribosomal protein S19 during early embryogenesis leads to reduction of erythrocytes in a zebrafish model of Diamond-Blackfan anemia. Hum Mol Genet 17: 3204-3211.

Valdez BC, Henning D, So RB, Dixon J, Dixon MJ. 2004. The Treacher-Collins syndrome (TCOF1) gene product is involved in ribosomal DNA gene transcription by interacting with upstream binding factor. Proc Natl Acad Sci 101: 10709-10714.

Van den Berghe H, Vermaelen K, Mecucci C, Barbieri D,

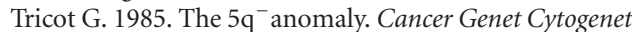
17: 189-255.

Vardiman JW, Harris NL, Brunning RD. 2002. The World Health Organization (WHO) classification of the myeloid neoplasms. Blood 100: 2292-2302.
Vlachos A, Rosenberg PS, Atsidaftos E, Alter BP, Lipton JM. 2012. Incidence of neoplasia in Diamond-Blackfan anemia: A report from the Diamond-Blackfan Anemia Registry. Blood 119: 3815-3819.

Volarevic S, Stewart MJ, Ledermann B, Zilberman F, Terracciano L, Montini E, Grompe M, Kozma SC, Thomas G. 2000. Proliferation, but not growth, blocked by conditional deletion of $40 \mathrm{~S}$ ribosomal protein S6. Science 288: 2045-2047.

Wan F, Anderson DE, Barnitz RA, Snow A, Bidere N, Zheng L, Hegde V, Lam LT, Staudt LM, Levens D, et al. 2007. Ribosomal protein S3: A KH domain subunit in NF- $\mathrm{kB}$ complexes that mediates selective gene regulation. Cell 131: 927-939.

Wang Q, Yang C, Zhou J, Wang X, Wu M, Liu Z. 2001. Cloning and characterization of full-length human ribosomal protein L15 cDNA which was overexpressed in esophageal cancer. Gene 263: 205-209.

Wanzel M, Russ AC, Kleine-Kohlbrecher D, Colombo E, Pelicci PG, Eilers M. 2008. A ribosomal protein L23-nucleophosmin circuit coordinates Mizl function with cell growth. Nat Cell Biol 10: 1051-1061.

Wise CA, Chiang LC, Paznekas WA, Sharma M, Musy MM, Ashley JA, Lovett M, Jabs EW. 1997. TCOF1 gene encodes a putative nucleolar phosphoprotein that exhibits mutations in Treacher-Collins syndrome throughout its coding region. Proc Natl Acad Sci 94: $3110-3115$.

Xiong X, Zhao Y, He H, Sun Y. 2011. Ribosomal protein S27-like and S27 interplay with p53-MDM2 axis as a target, a substrate and a regulator. Oncogene 30: 17981811.

Yadav GV, Chakraborty A, Uechi T, Kenmochi N. 2014 Ribosomal protein deficiency causes Tp53-independent erythropoiesis failure in zebrafish. Int J Biochem Cell Biol 49: $1-7$.

Yadavilli S, Hegde V, Deutsch WA. 2007. Translocation of human ribosomal protein S3 to sites of DNA damage is dependant on ERK-mediated phosphorylation following genotoxic stress. DNA Repair (Amst) 6: 14531462.

Yadavilli S, Mayo LD, Higgins M, Lain S, Hegde V, Deutsch WA. 2009. Ribosomal protein S3: A multi-functional protein that interacts with both $\mathrm{p} 53$ and MDM2 through its KH domain. DNA Repair (Amst) 8: 1215-1224.

Yang ZY, Jiang H, Qu Y, Wei M, Yan M, Zhu ZG, Liu BY, Chen GQ, Wu YL, Gu QL. 2013. Metallopanstimulin-1 regulates invasion and migration of gastric cancer cells partially through integrin $\beta 4$. Carcinogenesis 34: 2851 2860.

Yuan X, Zhou Y, Casanova E, Chai M, Kiss E, Grone HJ, Schutz G, Grummt I. 2005. Genetic inactivation of the transcription factor TIF-IA leads to nucleolar disruption, cell cycle arrest, and p53-mediated apoptosis. Mol Cell 19: 77-87.

Zhai W, Comai L. 2000. Repression of RNA polymerase I transcription by the tumor suppressor p53. Mol Cell Biol 20: $5930-5938$.

Zhang Y, Lu H. 2009. Signaling to p53: Ribosomal proteins find their way. Cancer Cell 16: 369-377.

Zhang Y, Wolf GW, Bhat K, Jin A, Allio T, Burkhart WA, Xiong Y. 2003a. Ribosomal protein L11 negatively regu- 
C. Deisenroth et al.

lates oncoprotein MDM2 and mediates a p53-dependent ribosomal-stress checkpoint pathway. Mol Cell Biol 23: 8902-8912.

Zhang YP, Wolf GW, Bhat K, Jin A, Allio T, Burkhart WA, Xiong Y. 2003b. Ribosomal protein L11 negatively regulates oncoprotein MDM2 and mediates a p53-dependent ribosomal-stress checkpoint pathway. Mol Cell Biol 23: 8902-8912.

Zhang C, Comai L, Johnson DL. 2005. PTEN represses RNA polymerase I transcription by disrupting the SL1 complex. Mol Cell Biol 25: 6899-6911.

Zhang J, Tomasini AJ, Mayer AN. 2008. RBM19 is essential for preimplantation development in the mouse. $B M C$ Dev Biol 8: 115.
Zhang Y, Wang J, Yuan Y, Zhang W, Guan W, Wu Z, Jin C, Chen H, Zhang L, Yang X, et al. 2010. Negative regulation of HDM2 to attenuate p53 degradation by ribosomal protein L26. Nucleic Acids Res 38: 6544-6554.

Zhang $\mathrm{X}$, Wang W, Wang $\mathrm{H}$, Wang $\mathrm{MH}, \mathrm{Xu}$ W, Zhang R. 2013. Identification of ribosomal protein S25 (RPS25)MDM2-p53 regulatory feedback loop. Oncogene 32: $2782-2791$.

Zhou X, Hao Q, Liao J, Zhang Q, Lu H. 2013. Ribosomal protein S14 unties the MDM2-p53 loop upon ribosomal stress. Oncogene 32: 388-396.

Zhu Y, Poyurovsky MV, Li Y, Biderman L, Stahl J, Jacq X, Prives C. 2009. Ribosomal protein S7 is both a regulator and a substrate of MDM2. Mol Cell 35: 316-326. 


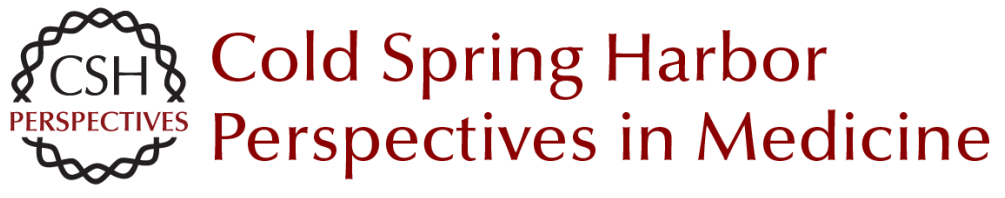

\section{The Evolution of the Ribosomal Protein-MDM2-p53 Pathway}

Chad Deisenroth, Derek A. Franklin and Yanping Zhang

Cold Spring Harb Perspect Med 2016; doi: 10.1101/cshperspect.a026138 originally published online October 6, 2016

\section{Subject Collection The p53 Protein}

Targeting the MDM2-p53 Protein-Protein Interaction for New Cancer Therapy: Progress and Challenges

Shaomeng Wang, Yujun Zhao, Angelo Aguilar, et al.

Structural Evolution and Dynamics of the p53

Proteins

Giovanni Chillemi, Sebastian Kehrloesser,

Francesca Bernassola, et al.

Exploiting the p53 Pathway for Therapy Chit Fang Cheok and David Philip Lane

The Regulation of Cellular Functions by the p53 Protein: Cellular Senescence

Crystal A. Tonnessen-Murray, Guillermina Lozano and James G. Jackson

The Transactivation Domains of the p53 Protein Nitin Raj and Laura D. Attardi

The Evolution of the Ribosomal Protein-MDM2p53 Pathway

Chad Deisenroth, Derek A. Franklin and Yanping Zhang

Somatic TP53 Mutations in the Era of Genome

Sequencing

Pierre Hainaut and Gerd P. Pfeifer

The Paradox of p53: What, How, and Why? Yael Aylon and Moshe Oren
Control of Cellular Aging, Tissue Function, and Cancer by p53 Downstream of Telomeres Caitlin M. Roake and Steven E. Artandi

Inherited TP53 Mutations and the Li -Fraumeni Syndrome

Tanya Guha and David Malkin

TP53 Mutations in Hypodiploid Acute Lymphoblastic Leukemia

Evan Q. Comeaux and Charles G. Mullighan

Transcriptional Regulation by Wild-Type and

Cancer-Related Mutant Forms of p53

Neil T. Pfister and Carol Prives

The Inherited p53 Mutation in the Brazilian Population

Maria Isabel Achatz and Gerard P. Zambetti

TP53 Mutations in Breast and Ovarian Cancer Laxmi Silwal-Pandit, Anita Langerød and Anne-Lise Børresen-Dale

p53 and the Carcinogenicity of Chronic Inflammation

Andrei V. Gudkov and Elena A. Komarova

Oncogenic Mutant p53 Gain of Function

Nourishes the Vicious Cycle of Tumor

Development and Cancer Stem-Cell Formation

Yoav Shetzer, Alina Molchadsky and Varda Rotter

For additional articles in this collection, see http://perspectivesinmedicine.cshlp.org/cgi/collection/ 